\title{
Behavioral Strategies for Constructing Nonviolent Cultures With Youth
}

\author{
A Review
}

\author{
MARK A. MATTAINI \\ MELISSA S. MCGUIRE \\ University of Illinois at Chicago
}

\begin{abstract}
Youth violence is widely recognized as a critical social issue in the United States, and many approaches to prevention have been developed in recent years. Emerging research suggests that only approaches that are deeply embedded in cultural, community, and organizational contexts are likely to be powerful enough to have a meaningful collective impact. No programs of this kind that are also truly practical and socially valid have yet reached a level where they can be regarded as well established, but data are beginning to appear that can guide community efforts. In this review, two classes of behavioral programming that appear promising as partial solutions to this need are identified: universal skills training and ecological strategies that focus on interlocking cultural practices. Progressive refinements in both are appearing through programs of developmental research. This paper reviews the state of the science in these efforts.
\end{abstract}

Keywords: violence prevention; youth violence; social skills; changing cultural practices

Violence and threats of violence, violent crime, and other forms of coercion are a major social problem in the United States (Sandhu, 2001). In fact, a strong case can be made that heavy reliance on violence and coercion is the central sociocultural challenge facing contemporary societies, both domestically and internationally (Sidman, 2001). Recent events on the world stage (e.g., in the United States and the Mideast) only strengthen this assertion. Violence, threats, and coercion among youth are an important subset of the overall problem not only because of their immediate effects, but also because they can persist into adulthood in both direct and subtle ways. The rates of some violent crimes among youth have declined substantially in

BEHAVIOR MODIFICATION, Vol. 30 No. 2, March 2006 184-224

DOI: $10.1177 / 0145445503259390$

(C) 2006 Sage Publications

184 
recent years in the United States, but there is little reason for complacency. Rates of assault have declined very little (Snyder, 2000), selfreports for many violent acts do not reflect the reductions suggested by arrest data (U.S. Surgeon General, 2001), and the rates of some violent crimes may again be increasing. In addition, if - as many believe - the rates of violent crime declined during the late 1990s in part because of a strong economy and a reduction in the number of young people, society remains ever at risk for increases in crime during periods of economic weakness and demographic change.

The incidence of violence is much higher in the United States than in most other developed countries, a pattern that has held for decades (Reiss \& Roth, 1993; U.S. Surgeon General, 2001). About 3,000 persons younger than 18 years of age were murdered each year in the United States during the early and mid-1990s (Kaufman et al., 1998). Young people between the ages of 12 and 24 become victims of violent crimes at least 2 million times each year, with peak risk between the ages of 16 and 19; the peak age for violent offending is just a bit higher (Perkins, 1997). Fourteen percent of high school students report carrying weapons to school, and more than one in three high school students does not feel safe at school (Josephson Institute of Ethics, 2001). Gay and lesbian youth are at particularly high risk for victimization; youth of color are at much higher risk than are Whites (Perkins, 1997).

Despite assertions to the contrary (Mirsky \& Siegel, 1994), most violence does not appear to be the result of brain pathology (Mattaini, Twyman, Chin, \& Lee, 1996). Rather, the primary roots of violence appear to lie in the overall social toxicity of contemporary cultures (Garbarino, 1999), many of which privilege individualism and acquisition above collective welfare, and rely on coercive processes as a primary means of managing social relations (Sidman, 2001). In addition, young people in the United States would have typically watched tens of thousands of simulated murders and other violent crimes in the media (major cultural institutions) by the time they reach adolescence (Lamberg, 1998). In lower income areas in the United States, it is common to find that anywhere from a quarter to a substantial majority of young people have personally witnessed violent crimes ranging from muggings to murder as a standard part of growing up (e.g., Bell \& Jenkins, 1993; Chapin \& Singer, 1999). 
Historian Roger Lane (1997) traces murder rates from origins in Medieval England through the entire history of the United States. There are many complexities in such an analysis; most murders of Native Americans and African American slaves were not recorded, for example, and many assumptions are required to arrive at even reasonable estimates until well into the 20th century. Nonetheless, Lane's careful research suggests that murder, and probably violence of other kinds, has been a serious problem from the beginning of American society; it is not a newly emerging crisis (for further historical perspective, see Martin, 1999). Violence in America wears many faces, from workplace violence (Watson, Williams, \& Ball, 2001) to ethnic violence (Fong \& Sandhu, 2001), from antigay hate crimes (Burlew \& Kocet, 2001) to domestic violence and child abuse, among many other forms. The problem is of long standing, and appears to be deeply integrated into U.S. culture.

Behavior analytic science supports these assertions. Sidman (2001) describes "the almost exclusive use of coercion in all spheres of human interaction" (p. 1) in contemporary Western society, despite overwhelming evidence that such reliance is ultimately damaging personally and collectively. Introducing his review of the effects of coercive control at all social levels from the family to international affairs, Sidman (2001) indicates that

Evidence from the analysis of behavior tells us that even when coercion accomplishes its immediate aim, it is in the long run self-defeating. Yes, we can get people to do what we want by threatening dire consequences if they do anything else, or to stop doing what we don't want by punishing those actions, but when we do, we sow the seeds of personal disengagement, isolation from society, neurosis, intellectual rigidity, hostility, and rebellion. (p. 2)

At the same time, evidence is accumulating that strategies and programs rooted in behavior analytic science have meaningful potential for reducing the incidence of violence, including violence among youth. Not surprisingly, given the discussion above, the data seem to suggest that the greatest power lies in interventions that address cultural practices, rather than targeting individual behavior. If the roots of violence lie in interlocking networks of cultural practices, it is not surprising that attention to those webs is likely to be necessary for lasting 
change. This review, therefore, focuses particularly on what is known, and not known, about constructing and maintaining practices that support alternatives to violence and coercion in organizational and community cultures.

\section{DIMENSIONS OF EFFECTIVE AND INEFFECTIVE PROGRAMS}

According to Mercy and Hammond (2001),

The worth of violence-prevention programs has been clearly demonstrated. We've learned through careful scientific demonstrations that participation in certain types of violence prevention programs can reduce the likelihood of involvement in violent behavior, and for those already involved, reduce the rate and seriousness of offending. (p. 1)

Biglan and Taylor (2000) argue that contrary to common perceptions about violence prevention in the scientific and policy communities, "the behavioral sciences have accumulated considerable evidence about populations to target for preventive interventions, the factors that contribute to problematic development, and the prevention programs that could modify risk and protective factors in order to prevent violent behavior" (p. 276).

Examples of programs with reasonable to excellent empirical support are the 10 programs identified by the Center for the Study and Prevention of Violence at the University of Colorado (Elliott \& Tolan, 1999) as Blueprint Programs - well-established programs for which detailed implementation blueprints have been, or are being, developed (Muller \& Mihalic, 1999). These range from universal strategies such as nursing visitation of young families and Big Brothers/Big Sisters to school-based skills training and multisystemic family treatment. A recent review by the U.S. Surgeon General (2001) expands the list of model and promising programs. For schools specifically, Lawler (2000) identified 20 research-based programs that have demonstrated utility in reducing violence and associated behavior problems. Cooper, Lutenbacher, and Faccia (2000) reviewed studies over a 20 -year period, and provide some guidance regarding particular strat- 
egies that may be useful for work with particular subgroups of children.

Still, no single approach has either proven universally acceptable across cultures and communities, or clearly demonstrated the power to substantially reduce the incidence of violence within a population over an extended period. Well-executed comparison studies are also lacking. For these reasons, Elliot and Tolan (1999) have argued for an applied "science of action" (p. 18), emphasizing action research in multiple ecological settings. Tolan (2001) further clarifies that preventive and interventive strategies and approaches are likely to be differentially effective depending on developmental considerations in transaction with the social ecology within which youth are embedded. If primary emphasis is placed on cultural change, adaptations responsive to local values, cultures, and resources are likely to be necessary in nearly every case (Fawcett, 1991). This is, of course, a serious challenge in taking programs to scale. Every program may need to look somewhat different in order to be effective, so careful monitoring using time-series (single-system) designs is clearly essential (Biglan, 1995); the assumption that identical procedures will produce the same outcomes in diverse settings cannot be justified.

\section{INEFFECTIVE APPROACHES}

A number of reviews have identified factors that are associated with ineffective preventive strategies. According to Astor, Vargas, O'Neal Pitner, and Meyer (1999), ineffective interventions are typically characterized by one or more of the following:

1. a singular focus on the source of the problem (e.g., only the child, or only the family) despite the extensive evidence that coercive and violent behavior is multidetermined;

2. viewing individuals as the carriers or vectors of violence, and therefore relying exclusively on programs such as therapy, skills training, peer counseling, and peer mediation, without targeting the larger networks within which behavior is embedded;

3. underuse of contextual strategies (e.g., relying on add-ons such as specialized curriculum modules rather than attending to social and organizational dynamics of everyday life in schools, other organizations, and communities); and 
4. a primary focus on hypothesized deficits of individuals or subpopulations of youth.

A recently released report on youth violence by the U.S. Surgeon General (2001) concurs with all of these points, and indicates that a number of very popular programs that fail to take a contextual approach must be regarded as ineffective at best, and may sometimes even be harmful. Among these are peer-led programs such as peer counseling and peer mediation, as well as the original Drug Abuse Resistance Education (DARE) program (which has recently been extensively reworked in response to those findings). It is important to note, however, that these are results of meta-analyses, which with some qualifications assume the equivalence of multiple programs that may in reality be very different. Peer mediation may be of some value with some groups under some circumstances (Kaplan, 1997). Some other forms of mediation apparently can be effective; victim-offender mediation, for instance, can reduce reoffending (Nugent, Umbreit, Wiinamaki, \& Paddock, 2001), and parent-child mediation has shown some evidence of effectiveness (Umbreit \& Kruk, 1997). Not surprisingly, programs that rely on punitive and coercive strategies have consistently been shown to be ineffective, and often damaging (Elliott \& Tolan, 1999).

\section{EFFECTIVE APPROACHES}

The American Psychological Association (1993) indicates that effective programs are grounded in well-validated theory and knowledge of youth development, and target known risk and protective factors. The Surgeon General's report (2001) provides further guidance:

Most highly effective programs combine components that address both individual risks and environmental conditions, particularly building individual skills and competencies, parent effectiveness training, improving the social climate of the school, and changes in type and level of involvement in peer groups.

Colvin and Sugai (1988) noted that although proactive teaching strategies are typically used in schools to address academic deficits, the 
most common approaches used to address social deficits tend to be punitive and reactive (see discussion in Mayer, 2001). Effective prevention projects in schools, however, are characterized by positive behavior change procedures rather than punitive ones; clear, positive simple rules, developed collaboratively; strong support for staff; efforts to minimize academic failure; social skills training as part of an integrated program; use of validated behavior change procedures; strong support for student involvement; and attention to and respect for student differences (Mayer, 2001).

Similar features are reported by Metzler, Biglan, Rusby, and Sprague (2001) as critical to effective behavior management programs, including the following:

1. emphasis on increasing positive reinforcement for appropriate social behavior,

2. active teaching of appropriate social behavior,

3. clear communication of a small number of rules,

4. consistent provision of corrective consequences for rule violation, and

5. ongoing monitoring of data to provide feedback for program development.

These guidelines generalize to preventing many forms of problem behavior including violence; Lawler (2000) identified many of the same factors as specifically characteristic of effective programs for violence prevention in school settings.

Again, the Surgeon General's report (2001) concurs, indicating that, "In schools, interventions that target change in the social context appear to be more effective, on average, than those that attempt to change individual attitudes, skills, and risk behaviors" (p. 13). Among specific recommendations drawn from programs regarded by the Surgeon General's staff as model or promising, are the following:

1. focusing on enhancing positive student behavior, attendance, and academic achievement through consistent rewards and monitoring;

2. use of behavioral techniques for classroom management;

3. establishing clear rules and directions; and

4. use of praise and approval, behavior modeling, token reinforcement, self-specification of contingencies, self-reinforcement, and behavior shaping. 
Protective factors for preventing violence included in the report include warm, supportive relationships with adults, recognition for involvement in positive activities, parental supervision, living in a strong community, and commitment to school. Even for reducing problem behavior, the Surgeon General's review suggests (a) ignoring, (b) reinforcing behavior that is incompatible with negative behavior, and (c) using disciplinary techniques such as soft reprimands, timeouts, and point loss or fines within token economies. Looking at the Surgeon General's report, it is clear that behavioral strategies have become mainstream, at least in the domain of violence prevention. Each list of characteristics of effective programs mentioned above indicates, in one way or another, that a constructional approach (Goldiamond, 1974) that teaches positive repertoires, ensures that use of those repertoires is heavily reinforced throughout the contextual setting, and reduces reliance on coercive and punitive procedures is key.

Many general reviews of the violence prevention literature are available (e.g., Center for the Study and Prevention of Violence, 1999; Reiss \& Roth, 1993; Tolan \& Guerra, 1994; U.S. Surgeon General, 2001; Wahler, Fetsch, \& Silliman, 1997). Our purpose in this article is narrower. Given the strong emphasis on context that is consistently emerging from the literature, the focus of this review is on approaches for constructing cultures that may shape and support prosocial repertoires inconsistent with violence and coercion among youth of middle and high school age and the adults with whom they are in regular contact. Skinner (1987) defined culture as "the contingencies of reinforcement maintained by a group" (p. 74), and identified cultural practices as a key unit of analysis (cf. Mattaini, 1996). In this review, we emphasize approaches that explicitly aim for collective changes in cultural practices within interlocking social networks, within cultures in Skinner's sense, which include organizations, families, peer groups, and often larger community networks as well.

A number of the programs with the strongest empirical support have relied extensively on outside research teams and programmatic supports that are unlikely to be duplicated under natural community conditions. Paraphrasing Moore (1994), Elliott and Tolan (1999) note, 
In many respects, our limited success in influencing prevention and intervention programming and policy is the result of failures to translate theoretical propositions and basic research findings into operational programs and policies that have some realistic chance of modifying the predisposing causes and conditions leading to violent behavior and that could be successfully implemented by local communities and agencies with their existing resources. (p. 18)

To address this challenge, this review emphasizes approaches that appear empirically promising, are consistent with the established principles for effective programs, are at least to some extent grounded in the power of the natural science of behavior, may have potential for practical application in everyday community settings, and have potential for having an impact on cultural networks. (Note that this work has not yet reached the stage where multiple clinical trials with extensive follow-up data, conducted by independent investigators, are generally available. The extent of available evidence supporting each of the strategies we discuss is clarified in the material that follows.) Programs targeting cultural change to reduce violence and coercion tend to be of two basic types, those that emphasize relatively universal skills training (as opposed to training focused only on "high risk" individuals), and those aiming at cultural change at multiple, interlocking ecological levels. Each of these general strategies will be considered in separate sections below.

\section{UNIVERSAL SKILLS TRAINING WITH YOUTH}

One partial step toward programs for constructing nonviolent cultures is universal skills training. Some skills training projects have substantial empirical support, and a case can be made that if a large enough number of individuals in a community or program setting are exposed to such skills training, those skills may become widespread cultural practices. Without explicit ecological attention to constructing contingencies of reinforcement supporting maintenance of positive behaviors, however, there is no guarantee that those behaviors will become firmly embedded in the culture (Mattaini, 2001a). Skills training is a common behavioral strategy for changing behavior 
among children and youth (e.g., Forman, 1993; LeCroy \& Daley, 2001; Rose, 1998), and has been widely applied and studied for more than two decades. Our focus here is on programs in which skills training has been applied relatively universally within organizations (e.g., schools, shelters) or peer groups in an effort to reduce the overall incidence of violence, threat, and coercive actions. In these cases, the goal is not to change the behavior of identified individuals, but rather to change the overall culture or climate among the group.

Not all such training approaches are effective. An example is the original Violence Prevention Curriculum for Adolescents (ProthrowStith, 1987), which was widely adopted across the United States. This 10 -session, school-based curriculum viewed anger as a normal and potentially constructive emotion that students need to learn to deal with in healthy and nonviolent ways, and therefore placed a strong emphasis on anger management and handling arguments effectively. An evaluation conducted by the program's developers (DeJong, Spiro, Wilson-Brewer, Vince-Whitman, \& Prothrow-Stith, n.d.), however, suggested that the curriculum produced only limited behavior change (improvement by self-report on one of seven measures). The National Research Council described these results as disappointing, indicating that "the results of this evaluation are not persuasive that this approach is helpful in reducing aggressive behavior by high school students" (Reiss \& Roth, 1993, p. 19). Hausman, Pierce, and Briggs (1996) did not find statistically significant changes in suspension rates between a school in which the curriculum had been widely implemented and another school without exposure. They did, however, find that a special classroom arrangement that included emphasis on communitybuilding and extensive family contact, in addition to use of the curriculum, produced a $71 \%$ reduction in suspensions.

Farrell and Meyer (1997), using a modification of Prothrow-Stith's approach that emphasized "creating a safe environment where children are willing to share their thoughts and to respect those of others" (p. 980), found a small but significant comparative reduction in rate of violent behavior among boys (but not girls) by self-report. Hausman, Spivak, and Prothrow-Stith (1995), using telephone survey methods, compared the relative effects of (a) workshop or classroom activities, (b) individual discussions of violence and conflict resolution, and (c) community-wide mass media efforts, and found that only the media 
strategy appeared to produce meaningful, if modest, effects on knowledge and attitudes. Prothrow-Stith in recent years has focused much more extensively on efforts to shift community context than on narrow anger-management approaches. One of the principal contributions of these successive efforts by Prothrow-Stith and other investigators using her materials is a progressive movement toward attending more intensively to the broader sociocultural matrices within which youth behavior occurs.

We have identified seven behaviorally based universal skills training programs and curricula that are either well supported or appear promising. All emphasize the development of skills known to be associated with reducing problem behavior and increasing prosocial alternatives. Each is briefly described in the material that follows.

\section{AGGRESSION REPLACEMENT TRAINING (ART)}

The current implementation of ART is the result of many years of developmental research by Goldstein, Glick, and colleagues (Glick \& Goldstein, 1983; Goldstein, Glick, \& Gibbs, 1998). The curriculum is designed to support the development of social skills among aggressive adolescents and children using a combination of interventions including skills training ("skillstreaming"), anger management, and moral education. The program is implemented over a 10-week period, typically in three hourly sessions per week, although it has been adapted for other temporal arrangements. ART has been implemented in a variety of settings, including schools, detention centers, and mental health facilities.

Skillstreaming is the behavioral component of ART. Fifty specific skills are taught using modeling, role-playing, and performance feedback as well as techniques supporting the transfer of training to natural settings. The affective component of ART focuses on anger management. In this training, youth are prepared for handling social situations involving the coercive behaviors of others. They learn a sequence of anger control responses, including identification of triggers for anger, calming self-statements, and relaxation techniques. Moral reasoning training, the cognitive component of ART, provides additional support for the skillstreaming and anger control interventions. Moral dilemmas are employed to provide real-life social situa- 
tions for adolescents to practice responding using newly acquired repertoires of prosocial behavioral skills.

A number of studies support the effectiveness of ART in producing behavior change. In a controlled evaluation in a residential facility for male youth $(N=60)$, significant intervention effects were found (Goldstein \& Glick, 1987). Acting-out and impulsiveness were reduced among youth who participated in the intervention as compared to the controls, both as rated by observers on a weekly basis, and in pre- and posttest surveys. However, no significant changes were demonstrated for moral reasoning. In a replication in a male correctional facility $(N=51)$, Goldstein and Glick (1987) found similar intervention effects. In this study, however, significant effects were found for both moral reasoning and behavior changes. Goldstein and Glick (1994a, 1994b) also found significant reductions in rearrest rates ( $15 \%$ for participants, compared to $43 \%$ for controls) for youth released from a correctional facility, and for arrest rates of gang members (13\% vs. 52\%). Similar results were found by Leeman, Gibbs, Fuller, and Potter (1991) in their work with juvenile offenders in a medium-security facility.

Nugent, Bruley, and Allen (1998) conducted an interrupted timeseries evaluation of an abbreviated version of ART, a 15-day package that excluded the moral reasoning component, over a 519-day period in a short-term shelter for runaway youth. Outcome measures focused on staff-recorded antisocial behaviors of the residents (ASB). Autoregressive Integrated Moving Average (ARIMA) analysis indicated a $20 \%$ decrease in the ASB rate and a 17\% decrease in ASB incidents after implementation of the ART program. In separate analyses by gender, the researchers found a $14 \%$ decrease in the mean weekly number of antisocial incidents for males after exposure to ART, and a $29 \%$ decrease for females (Nugent, Bruley, \& Allen, 1999). Overall, ART should be regarded as well supported, producing modest to strong effects under a range of conditions.

\section{CAN PROBLEM SOLVE (ICPS)}

ICPS, originally referred to as Interpersonal Cognitive Problem Solving program, is a school-based primary prevention curriculum (Shure, 1992; Shure \& Spivak, 1982) that is the product of more than 
35 years of research. Developmentally appropriate versions of the ICPS materials, designed specifically for preschool, kindergarten and primary grades, and elementary grades, are available. The program is based on the premise that the development of interpersonal cognitive skills is the most effective means to ameliorate antisocial behavior in children and seeks to teach children how to resolve or prevent interpersonal problems. The program provides classroom lessons, and encourages the use of dialogues, role-playing, and games to advance learning. Lessons are categorized as teaching "pre-problem-solving" or problem-solving skills (Shure, 1992). Lessons in pre-problemsolving skills are foundational, familiarizing children with verbal repertoires on which problem-solving skills develop. Problem-solving lessons teach children how to generate alternative solutions, and to anticipate consequences associated with each. In addition to materials for educators, the developers have produced a training manual, Raising a Thinking Child (Shure, 1999), for use by parents.

Well-controlled research with both preschool- and elementary-age populations indicates that ICPS can significantly improve cognitive problem-solving abilities, and reduce inhibition and impulsivity (Greenberg, Domitrovich, \& Bumbarger, 2001). Results had been maintained at 1-year follow-up (Greenberg et al., 2001). Hawkins, Catalano, Kosterman, Abbott, and Hill (1999) conducted a nonrandomized controlled study to investigate the long-term impact of an adolescent health-risk behavior intervention for children $(N=598)$, in which ICPS was combined with teacher training, parent education, and social competency training. The children selected for the study were from a high-crime, multiethnic community in Seattle. By age 18, children involved in the program from first grade were less likely to commit acts of violence ( $48.3 \%$ vs. $59.7 \%, p=.02)$; abuse alcohol $(15.4 \%$ vs. $25.6 \%, p=.04)$; engage in sexually promiscuous behavior $(72.1 \%$ vs. $83.1 \%, p=.02)$; and become a parent $(17.1 \%$ vs. $26.4 \%$, $p=.06)$. In addition, students reported more commitment to school $(p=.03)$, more attachment to school $(p=.006)$, higher grade point averages $(p=.01)$, and fewer conduct problems in school $(p=.02)$ as compared to controls. No significant effects were found for a late intervention group who received the intervention only in Grades 5 and 6. Overall, ICPS should be regarded as a well-supported program, which for best effects should probably be implemented early. 


\section{RESPONDING IN PEACEFUL AND POSITIVE WAYS (RIPP)}

RIPP, which is based on social cognitive learning theory and the Health Promotion Model, promotes alternatives to violence by attempting to reduce risk factors (Thornton, Craft, Dahlberg, Lynch, \& Baer, 2000). The program, designed for use with sixth through eighth graders, was developed in part from Prothrow-Stith's Violence Prevention Curriculum. The curriculum-based approach consists of 25 sessions (one session per week) and emphasizes both knowledge and social skills training for conflict resolution and positive communication, to empower youth to make nonviolent behavioral choices. Classroom lessons and activities include team building exercises, role-playing, group work, and cognitive rehearsal (Farrell, Meyer, Kung, \& Sullivan, 2001).

A controlled study $(N=626)$ of RIPP by Farrell, Meyer, and White (2001) was conducted at three urban schools with predominantly African American sixth-grade students. A schoolwide peer mediation program, available to all students (both control and intervention), was implemented concurrent with RIPP. Outcome measures included violent behaviors, in-school suspensions, and out-of-school suspensions. Results from the Problem Situation Inventory indicated that positive intervention effects were found for knowledge acquired about skills to use, but self-reports did not demonstrate significant effects for using the skills in vivo. Students in the intervention group were found to have reduced rates of fighting, carrying weapons, and suspensions, as well as increased rates of utilizing peer mediation, but controlling for attrition rates and group differences, significant effects remained only for in-school suspensions and weapon carrying. Perhaps importantly, RIPP appeared to have the greatest effects for students who were initially more aggressive. The researchers concluded that better results could have been garnered by extending the program universally throughout the school and by addressing other risk factors within the child's larger environment (such as within the home).

In a subsequent study (Farrell, Valois, \& Meyer, 2002) conducted in a rural middle school ( $N=204$ at pretest, reduced to 117 at followup), the effects of RIPP with one pod of sixth-grade students were compared to a similar pod in the same school. RIPP produced statistically significant improvements in knowledge, approval of violent 
behavior, peer support for nonviolence, peer pressure to use drugs, physical aggression, drug use, and peer provocation ( 7 of 11 outcome variables) at the end of the first (sixth-grade) year. Although effect sizes are provided, it is not possible to determine, from the manner in which the data are reported, the absolute levels of behavior, or the clinical significance of what may be modest differences. In the subsequent year, RIPP was implemented schoolwide; differences between the experimental group and the controls were no longer significant by the end of that year. Although the authors indicate that "many of the effect size estimates for the intervention decreased only slightly from posttest to follow-up," the accompanying table included reductions from -.72 to -.16 (knowledge), .47 to .18 (drug use), and .28 to .01 (physical aggression), with apparent increases in some problem behaviors from the previous year. As the authors note, however, in the second year there was no no-treatment control group to contrast these results with. It may be that the levels of increase would have been greater without the intervention. The schoolwide implementation during the seventh grade year for participants may also have produced a leveling effect among all youth, with the sixth-grade program producing an effect only during sixth grade. Overall, the data suggest that the intervention appeared to have some positive effects, and certainly support further development and testing.

\section{VIEWPOINTS}

Viewpoints is designed to address cognitive deficits associated with aggressive behavior, such as the inability to find alternative solutions to conflict or anticipate negative consequences of aggressive behavior (Guerra, Moore, \& Slaby, 1995; Guerra \& Slaby, 1990). The program emphasizes the development of prosocial behaviors as a means to reduce or transform antisocial behaviors. It is curriculumbased and consists of 12 sessions that teach eight specific steps for handling social conflicts. Social skills related to problem solving, impulse control, empathy and prosocial attitudes, and anticipating potential negative consequences are included. Real-life situations are used in the curriculum to promote practice using problem-solving skills. Program facilitators are expected to be responsible for teaching the lessons as well as modeling positive behaviors. 
A controlled evaluation of Viewpoints $(N=120)$ was conducted with male and female adolescents residing in a correctional facility (Guerra \& Slaby, 1990). The intervention included 12 sessions of problem-solving skills for Viewpoints groups, whereas controls included attention-control groups receiving training in basic academic skills or career counseling, and no-treatment groups. Significant main effects by group were found for social problem solving (problem definition, goal selection, number of facts, number of solutions, number of consequences, effectiveness of second best solution), and for beliefs supporting aggression (aggression as legitimate response, aggression increases self-esteem, aggression necessary to avoid a negative image, and victims deserve aggression). In addition, results on the Behavior Rating Scale indicated significant main effects for aggressive behavior, impulsive behavior, and inflexible behavior. However, no differences between groups on recidivism rates were found at the 24-month follow-up.

Viewpoints was also incorporated into the Washington Community Violence Prevention Program (WCVPP). In a controlled evaluation of the WCVPP package with fifth and sixth graders $(N=250)$, pre- and posttests using vignettes were administered (Gainer, Webster, \& Champion, 1993). Positive outcomes were found for recognition of potential social conflicts and identifying negative consequences of aggressive behavior. No effects were demonstrated for use of nonviolent solutions in conflict situations. In addition, the fifth-grade control group provided a greater number of nonviolent solutions for the vignettes than did the treatment group. Skroban, Gottfredson, and Gottfredson (1999) conducted a 5-year comparison study of a schoolwide social competency program that incorporated Viewpoints along with a number of other components, including mentoring, cognitive-behavioral instruction, career exploration and decisions, cognitive self-instruction, life skills training, social problem solving, cooperative learning, and tutoring. No significant effects for the combined program were demonstrated, but the results are difficult to interpret given the multiple components involved. 


\section{RESOLVING CONFLICTS CREATIVELY (RCCP)}

RCCP is a curriculum-based primary prevention program for kindergarten through 12 th grade. The program is based on social-cognitive learning theory and emphasizes that "aggressive and violent behavior is learned and therefore can be reduced through education." (Aber, Brown, \& Henrich, 1999, p. 4). The program endeavors to teach children that they have choices in the way they handle conflicts. Teachers provide the curriculum, which consists of 51 weekly 30 - to 60-minute lessons, in a workshop format. Lessons stress skill enhancement for resolving conflict, respect for cultural differences, and awareness among children of their role in contributing to peace. Core social skills such as effective communication, listening skills, identification and expression of feelings, anger management, conflict resolution, cooperative behavior, and accepting intergroup differences are major curricular components. In an effort to change the "culture of the classroom" (Aber et al., 1999, p. 4), and ultimately the culture of the school, a multicomponent approach is employed that involves student mediators, motivated volunteer teachers, school administrators, and parents. Parent workshops include content similar to that offered to teachers, with the addition of material related to the developmental needs of children.

A relatively large (overall $N=5,053$ ) evaluation of short-term program effects (Aber, Jones, Brown, Chaudry, \& Samples, 1998) compared the impact of three levels of program exposure (none, low, and high). High exposure was defined as high classroom instruction with moderate levels of teacher training, low exposure involved minimal classroom instruction and high levels of teacher training, and no exposure indicated either no or very little classroom instruction and teacher training. Outcome measures for the study included hostile attributional bias and normative beliefs about aggression. The highexposure program produced the most powerful effects. However, the program appeared to be of greatest benefit to older, female youth who were not considered to be at risk for violent or aggressive behavior. 


\section{PROMOTING ALTERNATIVE THINKING STRATEGIES (PATHS)}

PATHS, a Blueprint Program, is a school-based curriculum intervention designed for children from kindergarten to Grade 5 (Greenberg $\&$ Kusche, 1998). The curriculum was designed to address behavior and affective disorders while facilitating the development of social and emotional competency of children, through teaching problemsolving skills, emotional literacy, and social skills. The program emerges from the integration of several conceptual frameworks (only some of which are behavioral), including the ABCD (affective-behavioral-cognitive-dynamic) model, ecobehavioral systems approaches, neurobiological science, psychodynamic education, and emotional awareness theory (Greenberg \& Kusche, 1998). Lesson plans and classroom activities include participation in dialogues, role-playing, modeling, and social and self-reinforcement, all of which are consistent with behavioral theory and research. In this curriculum, children learn identification, expression, and regulation of emotions; the difference between emotions and behaviors; impulse control; and recognition and interpretation of social cues. Effective implementation of the program is seen as requiring integration of lessons into the regular curriculum. Activities for use outside of the classroom are also provided, as are program materials for parents that support behavior change and affective learning at home.

A randomized study by Greenberg, Kusche, Cook, and Quamma (1995) examined changes in emotional understanding among children. Participants were 286 children in 30 classrooms (Grades 1 to 3) in the Seattle area. Subsamples of both regular education and "at risk" or special needs children were selected. The treatment group was composed of 130 children, of which 47 were special education students. The control group consisted of 156 children, including 47 special needs students. Results after one academic year were mixed. Significant intervention effects were found for feelings vocabulary (no effect for special education children) and changing feelings. Special education children showed improvement in the rules for emotional display domain whereas regular education children did not. In addition, the special education children showed greater positive changes in the changing emotion domain than did the regular education subsample. No significant effects were found for general questions 
about feelings, understanding simultaneous feelings, discussion of own emotional experiences, and cues used to recognize emotions. However, for those domains with no intervention effects, developmental improvements were noted, for example for the ability to provide personal examples of the five basic feelings, cues for recognizing emotions, and understanding simultaneous feelings.

PATHS has also been combined with the Fast Track model (Conduct Problems Research Group, 1992), which provides intervention for high-risk children within their broader social context at the earliest possible age (Conduct Problems Research Group, 1999a, 1999b). Results suggest that the combined program can produce reductions in aggression, improvements in classroom atmosphere, improved skills, and reductions in special education referrals (Conduct Problems Research Group, 1999b; Greenberg et al., 2001). (Programs focused on particular youth are generally outside the scope of this article, and readers are referred to the original publications for more information on this combined program.)

\section{SECOND STEP}

Second Step (Committee for Children, 1997) is a school-based social skills program focused on children from preschool through Grade 9. The curriculum, which emphasizes the development of social competence, includes empathy training as well as skills training in impulse control and anger management. The program also addresses behaviors thought to be predictors of future antisocial acts, including impulsiveness, bullying, threatening, and disruptive behaviors. Videos, prepared vignettes, and role-playing are used to enhance the learning experience. In addition, the Second Step program offers a video-based parent program to introduce parents to the curriculum so that they can reinforce skills learned in the classroom.

A randomized evaluation of Second Step by Grossman et al. (1997) found a modest positive effect for the treatment group as compared to controls. The investigators also found that physical aggression increased for the control group during the school year, whereas the treatment group maintained gains at the 6-month follow-up. Orpinas, Parcel, McAlister, and Frankowski (1995) evaluated the Second Step program with 10 classes of sixth graders $(N=223)$. The researchers mea- 
sured changes in knowledge and skills, attitudes toward violence when provoked, and self-efficacy. Significant intervention effects were found for knowledge and skills, but there was no significant change in violence prevention attitudes, or in self-efficacy measures. The intervention effects found were not maintained at a 3-month follow-up. A cross-sectional study of eight urban schools $(N=9,000)$ conducted by Orpinas et al. (2000) found no reduction in aggressive behaviors associated with the program. In this study, exposure to community violence and parental attitudes about fighting at school were found to be the strongest predictors of future violence. The investigators suggested, on the basis of their findings, that effective interventions should begin before middle school, "explore social and environmental intervention strategies, and involve parents and community members" (p. 45).

Overall, the results reported for universal skills training programs suggest that some may have a meaningful impact on patterns of transactions within cultural entities, although not all do. Many require substantial investments of both training and classroom time, which can lead to problems in feasibility and implementation integrity. In many cases, the outcomes studied have focused on the behavior of individuals, rather than on overall incidence within cultural networks, but in some cases aggregate changes have been documented (e.g., Nugent et al., 1998). In most of the projects and studies discussed above, however, the extent to which contextual supports-known to be important for substantial change-have been constructed and maintained is unclear, although in many cases evaluations have called for greater attention to such contextual variables. A second set of behavioral programs focuses specifically on constructing supportive cultural contexts among peer, family, organizational, and community networks. Such strategies may be important for achieving stable and substantial collective changes in the incidence and prevalence of violent, threatening, and coercive behaviors.

\section{UNIVERSAL, ECOLOGICAL STRATEGIES}

Universal ecologically based strategies, as discussed here, are those that are explicitly designed to shift practices in entire cultural 
networks (large and small), for example, classroom culture, family culture, school culture, or community culture. Such strategies ordinarily do not focus only on youth behavior, but rather extend comparable attention to the actions of adults, peers, families, and actors within larger systems as well, aiming for integrated collective change among all actors. Many programs of this type use schools as a nexus, given that those settings offer access to a large number of youth at one time and place. A number of ecological strategies have also been implemented using community centers, community-based organizations, recreation programs, churches, and other cultural networks as the central focus, however. Most ecological projects extend beyond the focal system into the family and community networks in which youth and adults participate. Several of these approaches also have deep roots in behavior analysis, and are clearly more consistent with the identified features of effective programs (e.g., attention to contextual supports, consistent positive reinforcement in vivo) than any skills training package alone can be. We have identified eight ecological strategies that aim for universal impact within organizational or community networks, are grounded in or highly consistent with behavioral principles, and appear empirically promising.

\section{THE GOOD BEHAVIOR GAME}

More than three decades ago, Barrish, Saunders, and Wolf (1969) developed a procedure that they termed the Good Behavior Game (GBG). The study employed a simple procedure in which a fourthgrade classroom was divided into two teams, instances of disruptive behavior were recorded, and the team with the fewest disruptions earned extra privileges (both teams could do so if both achieved rates below an established criterion). In the class periods in which the game was used, the number of disruptions dropped dramatically. Embry (2002) recently reviewed approximately 20 replications of these results across a range of settings, with children and youth of a wide range of ages and development levels, including relatively well-controlled experimental studies (e.g., Kellam, Ling, Merisca, Brown, \& Ialongo, 1998). From this examination, Embry concludes that the game, particularly with recent refinements (e.g., the PAX Acts Game, Embry \& Straatemeier, 2001), has broad potential applicability as a 
"behavioral vaccine" that may be protective against antisocial behavior as much as several years later.

The GBG is important for two reasons. First, among behaviorists the consistent findings of the utility of relatively simple, reinforcement-based behavior management techniques like the GBG with both normal and developmentally delayed children and youth contributed to a professional culture in which the power of such interventions came to be broadly recognized. Many of the other approaches described below emerged out of this culture, even for those who may never have heard of the game. Secondly, the GBG itself is promising as a low-cost, straightforward, accessible technology that can easily be implemented in everyday settings, and can be modified to be compatible with each, because the underlying principle is robust. Embry's review suggests that the biggest challenge may be to ensure that necessary maintenance procedures are arranged, an issue for many of the approaches reviewed here, because consistent application is generally necessary to achieve cultural change.

\section{THE WORK OF G. ROY MAYER AND COLLEAGUES}

Several of the programs and strategies discussed below have roots in the pioneering work of the behavior analyst G. Roy Mayer and his colleagues. In the late 1970s, Mayer and colleagues developed a program in public elementary and junior high schools in Los Angeles County that focused on decreasing antisocial and increasing prosocial behavior (Mayer \& Butterworth, 1979; Mayer, Butterworth, Nafpaktitis, \& Sulzer-Azaroff, 1983). The program relied on two central strategies: dramatically increasing the use of positive reinforcement within the school, and ensuring that academic work was carefully calibrated for each student. Strong results were found across a number of replications, producing dramatic reductions in vandalism (a marker variable for antisocial behavior) relative to control schools, significant improvements in discipline, and improvements in academic achievement. This project was particularly important in that it introduced technologies (e.g., written recognition notes) that have been replicated in other projects discussed below, and in its finding that work with some staff could produce changes in behavior over time even among staff who were not explicitly trained. 
Mayer has continued in subsequent decades to develop related projects, including the one that produced dramatic changes in the behavior of ninth graders at high risk of dropping out (on task from 8 to $35 \%$ at baseline, 70 to $100 \%$ with intervention, and substantial reductions in suspensions and dropouts, Mayer et al., 1993). In addition, Mayer has made substantial contributions to integrating and disseminating what is known about reducing youth violence and antisocial behavior in behavior analytic terms (Mayer, 1995, 2001). Mayer's work is important in clarifying that relatively straightforward behavioral technologies can produce substantial change with relatively small investments of professional time, and in demonstrating once again the power of positive reinforcement to dramatically shift youth behavior.

PeaceBuilders

The PeaceBuilders program built on Mayer's work; the primary original developer, Dennis Embry, is also a behavior analyst. PeaceBuilders is a school-anchored but community-wide approach to violence prevention through improvement of school climate among elementary school children (Embry, Flannery, Vazsonyi, Powell, \& Atha, 1996). PeaceBuilders explicitly strives to systematically construct a culture that models and reinforces prosocial behavior, reduces sources of adult attention to inappropriate behavior, and increases peer attention to displays of positive behaviors and competencies. The program's goal is for schools to become peaceful learning environments where everyone (students, teachers, staff) learns, practices, and acquires the skills to ensure positive and respectful behaviors in order for students to achieve academic, personal, and interpersonal success. Children, and also adults, learn five principles for being a "PeaceBuilder": (a) praise people (increase in reinforcers), (b) give up put-downs (reduction in social aversives), (c) seek wise people as advisors and friends (modeling and supports for problem solving), (d) notice hurts (empathy building), and (e) right wrongs (responsibility building). In addition to its school emphasis, PeaceBuilders also includes parent education strategies and materials, collateral training for community volunteers, and media tools to extent support as broadly as possible into the community (Embry et al., 1996). The program was developed in part in response to recent biobehavioral 
research tracing factors affecting rates of prosocial and antisocial behavior (Embry \& Flannery, 1999). PeaceBuilders relies primarily, however, on constructing a new "way of life" within schools using basic behavioral tools with strong empirical support, and an explicit focus on contemporary marketing strategies.

In a number of schools in which the program has been well implemented, reductions of 50-60\% in disciplinary actions and fighting have been reported (www.peacebuilders.com). A relatively rigorous early evaluation of PeaceBuilders demonstrated statistically significant increases in prosocial behavior, and relatively fewer school nurse visits (particularly for fight-related injuries), in four PeaceBuilders schools, as contrasted with four nonequivalent control schools (Flannery et al., 1998). Levels of antisocial behavior were also lower in the study, although the reduction did not reach statistical significance. Additional larger scale evaluations funded by the Centers for Disease Control and Prevention, which regard the program as promising, are underway. The social validity of the PeaceBuilders program (discussed in a later section of this article) also appears strong.

\section{EFFECTIVE BEHAVIOR SUPPORT (EBS)}

EBS (Flannery, Sprague, \& Todd, 1996; Sugai \& Horner, 1994), a schoolwide program, is a system of training and technical assistance for schools with a primary focus on constructing and supporting positive behaviors throughout the school, relying on clear rules, incentives and other motivational techniques, and long-term commitment by staff. In addition to an emphasis on schoolwide climate, EBS projects also generally incorporate more intensive services for students who are at the highest risk.

Recognizing the utility of explicit skills training, in some current implementations EBS is being combined with universal skills training packages as described earlier in this article. For example, a 1-year combined EBS and Second Step implementation by Sprague et al. (2001) indicated that the program was effective in improving knowledge about social skills, as well as reducing office referrals for disciplinary action. This evaluation focused on schools (9 treatment, 6 comparison) as the unit of analysis. Staff in treatment schools received training on intervention components (20 hours), technical assistance 
(25-40 hours), implementation of the Second Step program (8 hours), and the EBS model (4 hours). Outcome variables included perceptions of school safety by school staff and local school council, school discipline, and social skills knowledge among students. The results indicate a significant decline in the number of office referrals (an average decrease of $36 \%$ for treatment middle schools, as compared to an increase of $82 \%$ for comparison schools, and an average decrease of $51 \%$ for treatment elementary schools, compared to an average decrease of $7.5 \%$ for comparison schools). Pre- and posttests administered indicate that all students in Grades 3 to 8 increased their knowledge of social skills (average increase 9\%). However, no significant effect was found for changes in perception of school safety as measured by the Oregon School Safety Survey.

CommunityBuilders

CommunityBuilders (Metzler et al., 2001) is an ambitious, community-wide strategy for reducing antisocial and increasing prosocial behavior among children and youth. CommunityBuilders integrates and extends the work of Mayer and colleagues, Embry and colleagues, and EBS (which provides the primary structure for the school component of CommunityBuilders). The strategy is specifically designed to be responsive to research related to the developmental trajectories of antisocial behavior among children and youth (e.g., Patterson, Reid, \& Dishion, 1992; Walker, Colvin, \& Ramsey, 1995). The community-wide program emphasizes increasing the incidence of four practices: "(a) praise, promote, and reward youths' worthwhile behavior, (b) monitor and supervise youths' activities, (c) set and enforce safe limits on youths' activities, and (d) foster youths' constructive relationships with people of all ages" (Metzler et al., 2001, p. 454). The school (EBS) component involves the promotion of four related behavioral expectations: (a) be respectful; (b) put-ups, not putdowns; (c) cooperate with others; and (d) solve problems peacefully.

The first published evaluation of CommunityBuilders (Metzler et al., 2001) examined the effects of the school component at a middle school in a small Oregon community, using two similar comparison schools for some analyses. The school component in this study involved relatively intensive consultation between the researchers and 
team members from the project schools. The evaluation examined the results of the school component across multiple variables, including the following:

1. use of repeated school climate surveys conducted with children counting praise and reward events,

2. counts of tickets provided on occasions of good behavior,

3. counts of praise notes generated by teachers,

4. counts of disciplinary referrals,

5. student reports of perceived safety,

6. student reports of harassment, and

7. measures of program implementation.

The results of this program were promising. Levels of positive reinforcement for prosocial behavior increased significantly. Reported aggressive social behavior declined, disciplinary referrals and harassment declined among some age groups (but not all), and perceptions of school safety improved. Reports of verbal and physical attacks also decreased, but a similar decrease was noted at a comparison school, making the results difficult to interpret. Particularly useful in this report is the incorporation of extensive time-series graphs, which are extremely useful in clarifying the data. Although the programs described by Mayer, the PeaceBuilders program, EBS, and CommunityBuilders, have substantial differences, the basic behavioral principles and strategies employed are clearly consistent across all four of these projects, which might be considered partial replications of a single basic approach.

\section{PEACE POWER}

The PEACE POWER strategy (Mattaini, 2001a, 2001b) for work with preteen and teenage youth, and recently being extended for work with younger children, is a fifth approach grounded in the same core behavior analytic principles. The development of the strategy also involved the confluence of behavior analytic science and certain indigenous practices that proved highly consistent with that science (Lowery \& Mattaini, 1999). PEACE POWER emphasizes constructing cultures of prosocial, nonviolent power (as an alternative to coer- 
cive power) with youth in organizations, families, and communities. In contrast to some of the other projects discussed, the PEACE POWER Working Group did not aim to develop a single program designed to be taken to scale without change in a variety of settings. Rather, consistent with Fawcett's (1991) principles of effective interventions that are likely to be sustained in everyday community settings, the intent is to offer a menu of empirically supported strategic tools from which local projects can draw and which they can adapt in constructing their own programs. PEACE POWER materials provide a variety of tools and activities directed toward increasing four core cultural practices: (a) recognize contributions and successes (targeting large increases in frequency of positive reinforcement events); (b) act with respect (decreasing incidents of coercion, threat, and punishment in part through differential reinforcement of incompatible behavior); (c) share power to build community (shaping repertoires that contribute to positive collective outcomes); and (d) make peace (use of healing repertoires in instances when injury has been done to interlocking transactional networks). Every PEACE POWER project is encouraged to attend to substantially increasing the incidence of each of these practices in some manner. The concept of shared power, giving staff, youth, parents, and the community-all stakeholdersmeaningful and powerful voices in the development of localized projects is heavily emphasized in the PEACE POWER strategy.

Given the emphasis of the strategy on the custom design of projects, the evaluation of PEACE POWER projects emphasizes the use of single-system time-series designs in each setting to track implementation variables (e.g., level of recognition provided) and outcomes (e.g., disciplinary referrals). The developers are working with a number of projects to develop a casebook of such evaluations. Preliminary results must be regarded as anecdotal at best, but consistent with the programs discussed so far, suggest that socially meaningful reductions in coercive and violent incidents, and increases in prosocial practices in the range of $50 \%$ are possible. Given the emphasis of the strategy on acceptability and maintainability with locally available resources, the collection of social validity data (see below) is also emphasized. In addition to the universal, ecological strategy, PEACE POWER also offers materials for life and leadership skills training 
based on many of the skills training programs discussed above, as well as integrated techniques for intensive ("high dose") work with highrisk youth that rely on the overall PEACE POWER framework (cf. Embry \& Flannery, 1999).

\section{BULLYING PREVENTION}

The best-studied bullying prevention intervention, the Bullying Prevention Program developed by Olweus (1993), also is highly consistent with behavioral principles, incorporating technologies such as increasing praise, role-playing, and consistent enforcement of rules. Bullying is a serious problem in U.S. schools, with at least $15 \%$ of youth targeted consistently, and nearly all targeted at some point. Similarly, most students participate in bullying on occasion, and over $10 \%$ do so regularly (Walker et al., 1995). Olweus's Bullying Prevention Program (a Blueprint Program) and variations like that developed by Walker and his colleagues (Walker, Hops, \& Greenwood, 1993) emphasize that bullying can cause severe emotional and sometimes physical damage, that mean-spirited teasing often leads to bullying, and that effective intervention must be ecological. Among the levels targeted in Olweus's program are the following:

1. organization-wide efforts (e.g., school conference day on bullying),

2. classroom strategies (e.g., group contingencies),

3. involvement of parents (e.g., parent circles to discuss responses to bullying problems), and

4. strategies for work with individuals involved, both victims and perpetrators.

At each of these levels, Olweus provides specific techniques; many of these techniques overlap with the common behavioral strategies described above, but generally target bullying behaviors specifically. The program emphasizes the shared responsibility of everyone in the setting to deal with the problem, for example by establishing the expectation that adults will actively intervene (and teaching them how to do so), and encouraging youth to give up the role of "passive accomplice" and take action to interrupt bullying (and teaching them how to do so). The results reported by Olweus in Scandinavia are 
impressive: reductions of $50 \%$ or more in bullying problems, with reductions increasing over time-at least for 2 years; reductions in other forms of antisocial behavior; and reported improvements in school climate. Several replications support the utility of the approach (U.S. Surgeon General, 2001).

\section{POSITIVE ACTION}

The Positive Action (Flay, Allred, \& Ordway, 2001) program is somewhat of an anomaly in this review, because it places a heavy emphasis on "self-concept," a construction that is usually viewed as an unjustified reification among behaviorists. The program is briefly mentioned here, however, because it focuses on an integrated, comprehensive approach to organizational change that includes attention to "school reorganization, teacher-student relations, parent involvement, instructional practices, and development of the self-concept of all parties (students, teachers, parents, community members)" (Flay et al., 2001, p. 75). Despite its multitheoretical and cognitive roots, however, the program in operation emphasizes that "people determine their self-concepts by what they do; that actions, more than thoughts and feelings, determine self-concept; and that making positive and healthy behavioral choices results in feelings of self-worth" (Flay et al., 2001, p. 75). The procedures used tend to be relatively consistent with those discussed for the explicitly behavioral programs and strategies described above; for example, "the school-climate program reinforces the curriculum learning by coordinating the efforts of the entire school in practicing positive actions to promote improved behavior and performance" (Flay et al., 2001, p. 77, italics in original).

The program has been implemented very widely, and is therefore clearly realistic, although requiring considerable staff and consultant time. It is important to at least examine, because it has produced decreases in disciplinary referrals of $78-85 \%$ in well-controlled studies, as well as substantial improvements in academic performance and reductions in arrests over a 3-year period (Cottrell, 1980; Flay et al., 2001). Given the multiple interventions included in the package, it is not possible to separate their differential effects. 


\section{CONCLUSIONS AND FUTURE DIRECTIONS}

The route to significant decreases in the incidence of violence, threat, coercion, and other antisocial behaviors does not appear to be through intensive treatment of a few damaged individuals, nor does treating individuals as vectors of antisocial behavior appear to be a promising route for prevention. As is the case with many other major social problems, understanding violence and coercion as cultural issues maintained by networks of interlocking practices appears to be a more productive direction (Biglan, 1995). As discussed above, several universal skills training programs, and some multilevel ecologically focused community programs, appear to have significant promise for operationalizing that perspective. Not surprisingly, basic behavioral strategies (e.g., skills training, substantial increases in positive reinforcement for prosocial behavior, moderation of aversives, and on-going, systematic evaluation) appear to be at the core of the effective interventions that have been identified, often explicitly.

A number of important areas for future work remain, however. The most important at this stage certainly are well-controlled, systematic replications of the programs described above and related variations with a variety of populations in a variety of settings. Given the promise of some of the programs described, considerable support and attention might profitably be directed to such replications. Also important, however, are the following: (a) work to refine existing programs to improve their fit with existing organizational and community settings, (b) extensive attention to social validity, and (c) the integration of prevention activities more seamlessly with intensive work with high-risk individuals, who ought not to be ignored in systemic projects, which they can reciprocally influence.

\section{REALISTIC PROGRAMS FOR EVERYDAY SETTINGS}

Fawcett, Mathews, and Fletcher (1980) (see also Fawcett, 1991) outline the requirements of "contextually appropriate behavioral technology" (p. 505), arguing that acceptable, sustainable community programs must be

1. effective, producing changes that are large, immediate, and apparent; 
2. inexpensive, so that they can be widely accessible;

3. decentralized, designed for implementation at the family, neighborhood, or other local levels;

4. flexible, presenting a menu of alternative approaches that allow and encourage participatory design;

5. sustainable with locally available resources;

6. simple enough that a wide range of persons can understand and implement the program; and

7. compatible with local values, experiences, and needs.

Factors such as simplicity and sustainability are important challenges in prevention programming. Complex programs, even if constructed from a set of well-supported components, may require extensive outside support, and still may prove difficult to implement with fidelity (e.g., Skroban et al., 1999).

As indicated by Fawcett (1991), intervention into interlocking cultural practices clearly needs to be a collaborative effort with community members and those who are embedded in existing institutional networks. It seems particularly unlikely, for example, that projects relying on the ongoing involvement of expensive outside consultants are likely to be maintained over the long term. The challenge, then, as suggested by Fawcett (1991), Embry (2002), Mattaini (2001b), and Elliott and Tolan (1999), is to develop relatively simple, highly robust strategies that can be easily adapted, implemented, and maintained within existing cultural entities. This is likely to require relatively transparent, simple, manualized approaches that not only provide clear guidance consistent with the science of behavior, but also are designed for flexibility of application that leaves room for local organizations and communities to construct projects in which they can take primary ownership.

Designing strategies that allow extensive local adaptation while maintaining the critical ingredients for effectiveness is a serious challenge, nonetheless. It has proven difficult in many fields to move from demonstrating efficacy in well-controlled research settings with considerable resources to demonstrating effectiveness in everyday settings in which competition for resources can be intense and expertise limited. Doing so with multicomponent interventions is particularly problematic. Many of the programs reviewed here involve multiple interventions with several systems, and it is possible that in a demon- 
strably effective program that combines, for example, a skills training curriculum and new methods of classroom instruction with activities addressed to school climate, each component must be well implemented to achieve success. Dismantling studies, therefore, that can test the relative effectiveness of stripped-down versions of programs are important.

\section{ACHIEVING SOCIAL VALIDITY IN ECOLOGICALLY BASED PROGRAMS}

However well grounded in the research an approach may be, if it is not implemented with integrity and adequate intensity over the necessary period of time, meaningful results cannot be expected; this is the problem highlighted by Elliott and Tolan (1999, quoted above). Social validity is, therefore, a critical consideration, particularly for universal, ecological strategies in which multiple interlocking practices among multiple groups of stakeholders are the targets for change. Social validity, as noted by Bailey (1991), involves marketing a "consumable product" (p. 445) that can be used by everyone. Language is one important consideration. Adopting everyday language that can function as establishing operations for effective practice, therefore, is critical (cf. Lindsley, 1991). Acceptability, another dimension of social validity, is often a critical issue, perhaps particularly in school settings. For example, Metzler and her colleagues (2001) reported that in their EBS study, "At times ... the greatest challenges to [the consultative] process involved uneven staff support for the schoolwide changes and insufficient engagement of some staff in the EBS process and activities" (p. 467).

Although data remain sparse, there is some indication that universal ecological programs can be both feasible and acceptable in everyday community settings. In a study of 200 teachers, Tingstrom (1994) reported that most found the GBG useful and acceptable, although those who did not "believe in" positive reinforcement were less likely to endorse it. Tingstrom also found, consistent with Fawcett's guidelines, that acceptability was positively correlated with effectiveness. Note that the GBG, in its many forms as described by Embry (2002), involves relatively modest response cost for those implementing it, and incorporates language and procedures that are congruent with 
everyday practices. Still, as Embry notes, although the game has been in the public domain for more than 30 years, adoption has been limited, and particular attention to marketing and packaging appears to be essential.

Teacher surveys of PeaceBuilders indicate that up to $77 \%$ of teachers believe that the program has made their jobs easier; they also report increases in time available for teaching. Teacher turnover also has been reported to decline after implementation of PeaceBuilders (www. peacebuilders.com). Similarly, in a small study of a well-implemented PEACE POWER project in an alternative high school in a smaller U.S. city (Humphrey \& Mattaini, 2001), 96\% of school staff reported that the strategy was "useful," or "very useful," and $100 \%$ reported that they would definitely $(79 \%)$ or possibly $(21 \%)$ recommend PEACE POWER to other schools $(N=43)$. In the same project, staff were asked to complete monthly rating forms on which they rated the importance of each of the four core PEACE POWER practices, as well as the frequency of those practices in their own setting. The average perceived importance of the four core practices was $3.9(S D=0.1)$ on a 4 -point scale $(1=$ not important, $4=$ very important $)$ over the course of 2 years of program implementation, suggesting that the level of social validity remained high. The incidence of each of the four practices showed an ascending trend during the first year, with maintenance or further increases for three of the four during the second year. The perceived incidence of recognition events (the central practice in this strategy) increased from 2.9 (just under often) at a single baseline point to 3.6 (approaching very often) on average in the second year; the incidence of the three other practices averaging at least often during that year.

\section{INTEGRATING INTENSIVE WORK WITH HIGH-RISK YOUTH}

In any setting in which universal strategies are applied, there will, of course, also be some young people whose prosocial repertoires and social supports are especially limited, and who are more involved in coercive, threatening, and violent behavior than are most others. There are several evidence-based approaches, consistent with behavior analytic science, for integrating intensive work with those young 
people and their families into broader contextual strategies, sometimes in relatively seamless ways. Used by themselves, such approaches are unlikely to dramatically affect the incidence of antisocial behavior within a population, but as an adjunct to universal strategies, they clearly can be useful. Without attention, these youth may also negatively affect overall results.

Embry and Flannery (1999) suggest that the distinction between violence prevention and intervention is counterproductive, stigmatizing some youth as problems. In fact, the same basic procedures are useful in both cases - the difference may be thought of as one of dose level along a continuum of proactive techniques. Although alternatives that are not defined in primarily clinical terms have not been extensively developed, significant attention is turning in that direction. One particularly promising alternative is the use of self-management techniques for youth involved in problem behavior, to assist them in reaching self-selected goals. Self-management systems typically provide reinforcement for both accurate monitoring and appropriate behavior. There is considerable evidence that self-monitoring projects can be quite effective in reducing antisocial and increasing prosocial behavior (Ninness, Ellis, Miller, Baker, \& Rutherford, 1995; Ninness, Fuerst, Rutherford, \& Glenn, 1991; Young, West, Smith, \& Morgan, 1991). Another alternative is Intensive PEACE POWER (Mattaini, 2001b), which explicitly focuses on increasing dose levels of universal interventions in an individualized manner for those who are not benefiting adequately from the universal program, and incorporates self-monitoring and self-management strategies in that process.

In conclusion, in our review we have identified a range of programs that appear to have potential to have an impact on the incidence of violent and coercive behaviors as well as prosocial behaviors within organizational and community cultures. None of these approaches have yet been validated at the level necessary to recommend them for universal application, and, in fact, it appears unlikely that any specific approach could be equally effective in widely diverse settings. Nonetheless, the emerging subdiscipline of the applied analysis of cultural practices, on which many of the programs discussed rely, appears to be positioned to contribute in a meaningful way to addressing this critical social problem. 


\section{REFERENCES}

Aber, J. L., Brown, J. L., \& Henrich, C. C. (1999). Teaching conflict resolution: An effective school-based approach to violence prevention. New York: National Center for Children in Poverty.

Aber, J. L., Jones, S. M., Brown, J. L., Chaudry, N., \& Samples, F. (1998). Resolving conflict creatively: Evaluating the developmental effects of a school-based violence prevention program in neighborhood and classroom context. Development and Psychopathology, 10, 187-213.

American Psychological Association. (1993). Violence and youth: Psychology's response. Washington, DC: Author.

Astor, R. A., Vargas, L. A., O’Neal Pitner, R., \& Meyer, H. A. (1999). School violence: Research, theory, and practice. In J. M. Jenson \& M. O. Howard (Eds.), Youth violence: Current research and recent practice innovations (pp. 139-171). Washington, DC: NASW Press.

Bailey, J. S. (1991). Marketing behavior analysis requires different talk. Journal of Applied Behavior Analysis, 24, 445-448.

Barrish, H. H., Saunders, M., \& Wolf, M. M. (1969). Good Behavior Game: Effects of individual contingencies for group consequences on disruptive behavior in a classroom. Journal of Applied Behavior Analysis, 2, 119-124.

Bell, C., \& Jenkins, E. (1993). Community violence and children on Chicago's southside. Psychiatry, 56, 46-54.

Biglan, A. (1995). Changing cultural practices. Reno, NV: Context Press.

Biglan, A., \& Taylor, T. K. (2000). Why have we been more successful in reducing tobacco use than violent crime? American Journal of Community Psychology, 28, 269-302.

Burlew, L. D., \& Kocet, M. (2001). Anti-gay hate crimes and violence: Counseling implications. In D. Sandhu (Ed.), Faces of violence: Psychological correlates, concepts and intervention strategies (pp. 193-211). Huntington, NY: Nova Science Publishers.

Center for the Study and Prevention of Violence. (1999). Blueprints for Violence Prevention. Boulder: University of Colorado, Institute of Behavioral Science, Center for the Study and Prevention of Violence. Retrieved February 8, 2002, from http://www.colorado.edu/cspv/ blueprints/

Chapin, M., \& Singer, M. I. (1999). Principles of military combat stress treatment related to children in high-risk environments. In D. J. Flannery \& C. R. Huff (Eds.), Youth violence: Prevention, intervention, and social policy (pp. 99-118). Washington, DC: American Psychiatric Press.

Colvin, G., \& Sugai, F. (1988). Proactive strategies for managing social behavior problems: An instructional approach. Education and Treatment of Children, 11, 341-348.

Committee for Children. (1997). Second Step: Violence prevention curriculum. Seattle, WA: Author.

Conduct Problems Research Group. (1992). A developmental and clinical model for the prevention of conduct disorders: The Fast Track program. Development and Psychopathology, 4, 509-527.

Conduct Problems Research Group. (1999a). Initial impact of the fast track prevention trial for conduct problems: II. Classroom effects. Journal of Consulting and Clinical Psychology, 67, 648-657.

Conduct Problems Research Group. (1999b). Initial impact of the fast track prevention trial for conduct problems: I. The high risk sample. Journal of Consulting and Clinical Psychology, 67, 631-647. 
Cooper, W. O., Lutenbacher, M., \& Faccia, K. (2000). Components of effective youth violence prevention programs for 7- to 14-year-olds. Archives of Pediatric and Adolescent Medicine, 154, 1134-1139.

Cottrell, M. C. (1980). The Positive Action program: An evaluation. Twin Falls, ID: Twin Falls School District.

DeJong, W., Spiro, A., III, Wilson-Brewer, R., Vince-Whitman, C., \& Prothrow-Stith, D. (n.d.). Evaluation summary: Violence prevention curriculum for adolescents. Newton, MA: Educational Development Center.

Elliott, D. S., \& Tolan, P. H. (1999). Youth violence prevention, intervention, and social policy: An overview. In D. J. Flannery \& C. R. Huff (Eds.), Youth violence: Prevention, intervention, and social policy (pp. 3-46). Washington, DC: American Psychiatric Press.

Embry, D. D. (2002). The good behavior game: A best practice candidate as a universal behavioral vaccine. Clinical Child \& Family Psuchology Review, 5, 273-297.

Embry, D. D., \& Flannery, D. J. (1999). Two sides of the coin: Multilevel prevention and intervention to reduce youth violent behavior. In D. J. Flannery \& C. R. Huff (Eds.), Youth violence: Prevention, intervention, and social policy (pp. 47-72). Washington, DC: American Psychiatric Press.

Embry, D. D., Flannery, D. J., Vazsonyi, A. T., Powell, K. E., \& Atha, H. (1996). PeaceBuilders: A theoretically driven, school-based model for early violence prevention. American Journal of Preventive Medicine, 12(Suppl. to No. 5), 91-100.

Embry, D. D., \& Straatemeier, G. (2001). The PAX Acts game manual: How to apply the good behavior game. Tucson, AZ: PAXIS Institute.

Farrell, A. D., \& Meyer, A. L. (1997). The effectiveness of a school-based curriculum for reducing violence among urban sixth-grade students. American Journal of Public Health, 87, 979984.

Farrell, A. D., Meyer, A. L., Kung, E. M., \& Sullivan, T. N. (2001). Development and evaluation of school-based violence prevention programs. Journal of Clinical Child Psychology, 30, 207-220.

Farrell, A. D., Meyer, A. L., \& White, K. S. (2001). Evaluation of responding in peaceful and positive ways (RIPP): A school-based prevention program for reducing violence among urban adolescents. Journal of Clinical Child Psychology, 30, 451-463.

Farrell, A. D., Valois, R. F., \& Meyer, A. L. (2002). Evaluation of the RIPP-6 violence prevention program at a rural middle school. American Journal of Health Education, 33(3), 167-172.

Fawcett, S. B. (1991). Some values guiding community research and action. Journal of Applied Behavior Analysis, 24, 621-636.

Fawcett, S. B., Mathews, R. M., \& Fletcher, R. K. (1980). Some promising dimensions for behavioral community technology. Journal of Applied Behavior Analysis, 13, 505-518.

Flannery, B. K., Sprague, J. R., \& Todd, A. (1996). Including students with behavioral challenges: Blending school-wide discipline and individual supports. In L. Power-deFur \& F. P. Orelove (Eds.), Inclusive schools: A comprehensive guide to successful implementation (pp. 227-244). Gaithersburg, MD: Aspen.

Flannery, D. J., Vazsonyi, A. T., Powell, K. E., Atha, H., Vesterdal, W., \& Embry, D. (1998). Longitudinal evidence of effective violence prevention: A randomized controlled trial of Peace Builders elementary school intervention. Unpublished manuscript, Kent State University, Institute for the Study and Prevention of Violence, Kent, OH.

Flay, B. R., Allred, C. G., \& Ordway, N. (2001). Effects of the Positive Action program on achievement and discipline: Two matched-control comparisons. Prevention Science, 2(2), 71-89. 
Fong, L. Y.-S., \& Sandhu, D. S. (2001). Ethnoviolence in America. In D. Sandhu (Ed.), Faces of violence: Psychological correlates, concepts and intervention strategies (pp. 155-170). Huntington, NY: Nova Science Publishers.

Forman, S. G. (1993). Coping skills interventions for children and adolescents. San Francisco: Jossey-Bass.

Gainer, P. S., Webster, D. W., \& Champion, H. R. (1993). A youth violence prevention program: Description and preliminary evaluation. Archives of Surgery, 128, 303-308.

Garbarino, J. (1999). Lost boys: Why our sons turn violent and how we can save them. New York: Free Press.

Glick, B., \& Goldstein, A. P. (1983). Aggression replacement training. Journal of Counseling and Development, 65, 356-362.

Goldiamond, I. (1974). Toward a constructional approach to social problems. Behaviorism, 2, 184.

Goldstein, A. P., \& Glick, B. (1987). Aggression replacement training: A comprehensive intervention for aggressive youth. Champaign, IL: Research Press.

Goldstein, A. P., \& Glick, B. (1994a). Aggression replacement training: Curriculum and evaluation. Simulation and Gaming, 25, 9-26.

Goldstein, A. P., \& Glick, B. (1994b). The prosocial gang: Implementing aggression replacement training. Thousand Oaks, CA: Sage.

Goldstein, A. P., Glick, B., \& Gibbs, J. C. (1998). Aggression replacement training: A comprehensive intervention for aggressive youth (Rev. ed.). Champaign, IL: Research Press.

Greenberg, M. T., Domitrovich, C., \& Bumbarger, B. (2001). The prevention of mental disorders in school-aged children: Current state of the field. Prevention \& Treatment, 4, 1-63. Retrieved on March 3, 2002, from journals.apa.org/prevention/volume4/pre0040001 a.html

Greenberg, M. T., \& Kusche, C. A. (1998). Blueprints for violence prevention: Book Ten: Promoting alternative thinking strategies. Boulder, CO: Center for the Prevention of Violence.

Greenberg, M. T., Kusche, C. A., Cook, E. T., \& Quamma, J. P. (1995). Promoting emotional competence in school-aged children: The effects of the PATHS curriculum. Development and Psychopathology, 7, 117-136.

Grossman, D. C., Neckerman, H. J., Koepsell, T. D., Liu, P., Asher, K. N., Beland, K., et al. (1997). Effectiveness of a violence prevention curriculum among children in elementary school. Journal of the American Medical Association, 277, 1605-1611.

Guerra, N. G., Moore, A., \& Slaby, R. G. (1995). Viewpoints: A guide to conflict resolution and decision making for adolescents. Champaign, IL: Research Press.

Guerra, N. G., \& Slaby, R. G. (1990). Cognitive mediators of aggression in adolescent offenders: 2. Intervention. Developmental Psychology, 26, 269-277.

Hausman, A., Pierce, G., \& Briggs, L. (1996). Evaluation of comprehensive violence prevention education: Effects on student behavior. Journal of Adolescent Health, 19, 104-110.

Hausman, A. J., Spivak, H., \& Prothrow-Stith, D. (1995). Evaluation of a community-based youth violence prevention project. Journal of Adolescent Health, 17, 353-359.

Hawkins, J. D., Catalano, R. F., Kosterman, R., Abbott, R., \& Hill, K. (1999). Preventing adolescent health-risk behaviors by strengthening protection during childhood. Archives of Pediatrics and Medicine, 153(3), 226-234.

Humphrey, J. E., \& Mattaini, M. A. (2001, May 27). PEACE POWER: A view from the field. Paper presented at Association for Behavior Analysis: An International Organization, 27th Annual Conference, New Orleans, LA.

Josephson Institute of Ethics. (2001). 2000 report card: Violence and substance abuse. Retrieved February 8, 2002, from http://www.josephsoninsitute.org/Survey2000/violence2000-commentary.htm 
Kaplan, N. M. (1997). Mediation in the school system: Facilitating the development of peer mediation programs. In E. Kruk (Ed.), Mediation and conflict resolution in social work and the human services (pp. 247-262). Chicago: Nelson-Hall.

Kaufman, P., Chen, X., Choy, S. P., Chandler, K. A., Chapman, C. D., Rand, M. R., et al. (1998). Indicators of school crime and safety, 1998 (Report No. NCES 98-251/NCJ 172215). Washington, DC: Departments of Education and Justice.

Kellam, S. G., Ling, X., Merisca, R., Brown, C. H., \& Ialongo, N. (1998). The effect of the level of aggression in the first grade classroom on the course and malleability of aggressive behavior into middle school. Development and Psychopathology, 10, 165-185.

Lamberg, L. (1998). Preventing school violence: No easy answers. Journal of the American Medical Association, 280, 404.

Lane, R. (1997). Murder in America. Columbus, OH: Ohio State University Press.

Lawler, M. K. (2000). School-based violence prevention programs: What works. In D. S. Sandhu \& C. B. Aspy (Eds.), Violence in American schools: A practical guide for counselors (pp. 247-266). Alexandria, VA: American Counseling Association.

LeCroy, C. W., \& Daley, J. (2001). Empowering adolescent girls. New York: Norton.

Leeman, L., Gibbs, J., Fuller, D., \& Potter, G. (1991). Evaluation of a multi-component treatment program for juvenile delinquents. Unpublished manuscript, The Ohio State University, Columbus.

Lindsley, O. R. (1991). From technical jargon to plain English for application. Journal of Applied Behavior Analysis, 24, 449-458.

Lowery, C. T., \& Mattaini, M. A. (1999). The science of sharing power: Native American thought and behavior analysis. Behavior and Social Issues, 9, 3-23.

Martin, C. L. (1999). The way of the human being. New Haven: Yale University Press.

Mattaini, M. A. (1996). Envisioning cultural practices. The Behavior Analyst, 19, 257-272.

Mattaini, M. A. (2001a). Constructing cultures of non-violence: The PEACE POWER Strategy. Education and Treatment of Children, 24, 430-447.

Mattaini, M. A., with the PEACE POWER Working Group. (2001b). Peace power for adolescents: Strategies for a culture of nonviolence. Washington, DC: NASW Press.

Mattaini, M. A., Twyman, J. S., Chin, W., \& Lee, K. N. (1996). Youth violence. In M. A. Mattaini \& B. A. Thyer (Eds.), Finding solutions to social problems: Behavioral strategies for change (pp. 75-111). Washington, DC: American Psychological Association.

Mayer, G. R. (1995). Preventing antisocial behavior in the schools. Journal of Applied Behavior Analysis, 28, 467-478.

Mayer, G. R. (2001). Antisocial behavior: Its causes and prevention within our schools. Education and Treatment of Children, 24, 414-429.

Mayer, G. R., \& Butterworth, T. (1979). A preventive approach to school violence and vandalism: An experimental study. Personnel and Guidance Journal, 57, 436-441.

Mayer, G. R., Butterworth, T., Nafpaktitis, M., \& Sulzer-Azaroff, B. (1983). Preventing school vandalism and improving discipline: A three-year study. Journal of Applied Behavior Analysis, 16, 355-369.

Mayer, G. R., Mitchell, L. K., Clementi, T., Clement-Robertson, E., Myatt, R, \& Bullara, D. T. (1993). A dropout prevention program for at-risk high school students: Emphasizing consulting to promote positive classroom climates. Education \& Treatment of Children, 16, 135146.

Metzler, C. W., Biglan, A., Rusby, J. C., \& Sprague, J. R. (2001). Evaluation of a comprehensive behavior management program to improve school-wide positive behavior support. Education and Treatment of Children, 24, 448-479. 
Mercy, J. A., \& Hammond, W. R. (2001). Learning to do violence prevention well. American Journal of Preventive Medicine, 20, 1-2.

Mirsky, A. F., \& Siegel, A. (1994). The neurobiology of violence and aggression. In A. J. Reiss Jr., K. A. Miczek, \& J. A. Roth (Eds.), Understanding and preventing violence: Vol. 2. Biobehavioral influences (pp. 59-172). Washington, DC: National Academy Press.

Moore, M. (1994). Violence in America: Mobilizing a response. Washington, DC: National Academy Press.

Muller, J., \& Mihalic, S. (1999). Blueprints: A violence prevention initiative (FS-99110). Washington, DC: U.S. Department of Justice, Office of Justice Programs.

Ninness, H. A. C., Ellis, J., Miller, W. B., Baker, D., \& Rutherford, R. (1995). The effect of a self management training package on the transfer of aggression control procedures in the absence of supervision. Behavior Modification, 19, 464-490.

Ninness, H. A. C., Fuerst, J., Rutherford, R. D., \& Glenn, S. S. (1991). Effects of self management training and reinforcement on the transfer of improved conduct in the absence of supervision. Journal of Applied Behavior Analysis, 24, 499-508.

Nugent, W. R., Bruley, C., \& Allen, P. (1998). The effects of aggression replacement training on antisocial behavior in a runaway shelter. Research on Social Work Practice, 8, 637-656.

Nugent, W. R., Bruley, C., \& Allen, P. (1999). The effects of aggression replacement training on male and female antisocial behavior in a runaway shelter. Research on Social Work Practice, 9, 466-482.

Nugent, W. R., Umbreit, M. S, Wiinamaki, L., \& Paddock, J. (2001). Participation in victimoffender mediation and reoffense: Successful replications? Research on Social Work Practice, 11, 5-23.

Olweus, D. (1993). Bullying at school. Cambridge, MA: Blackwell.

Orpinas, P., Kelder, S., Frankowski, R., Murray, N., Zhang, Q., \& McAlister, A. (2000). Outcome evaluation of a multi-component violence-prevention program for middle schools: The Students for Peace project. Health Education Research, 15(1), 45-58.

Orpinas, P., Parcel, G., McAlister, A., \& Frankowski, R. (1995). Violence prevention in middle schools: A pilot evaluation. Journal of Adolescent Health, 17, 360-371.

Patterson, G. R., Reid, J. B., \& Dishion, T. J. (1992). Antisocial boys: Vol. 4. A social interactional approach. Eugene, OR: Castalia.

Perkins, C. A. (1997). Age patterns of victims of serious violent crime (No. NCJ-162031). Washington, DC: U.S. Department of Justice.

Prothrow-Stith, D. (1987). Violence prevention curriculum for adolescents. Newton, MA: Educational Development Center.

Reiss, A. J., Jr., \& Roth, J. A. (1993). Understanding and preventing violence. Washington, DC: National Academy Press.

Rose, S. D. (1998). Group therapy with troubled youth: A cognitive-behavioral interactive approach. Thousand Oaks, CA: Sage.

Sandhu, D. (Ed.). (2001). Faces of violence. Huntington, NY: Nova Science Publishers.

Shure, M. B. (1992). I can problem solve (ICPS): An interpersonal cognitive problem solving program. Champaign, IL: Research Press.

Shure, M. B. (1999). Preventing violence the problem-solving way (Juvenile Justice Bulletin No. NCJ 172847). Washington, DC: U.S. Department of Justice, Office of Justice Programs.

Shure, M. B., \& Spivak, G. (1982). Interpersonal problem-solving in young children: A cognitive approach to prevention. American Journal of Community Psychology, 10, 341-356.

Sidman, M. (2001). Coercion and its fallout. Boston: Authors Cooperative.

Skinner, B. F. (1987). Upon further reflection. Englewood Cliffs, NJ: Prentice Hall. 
Skroban, S. B., Gottfredson, D. C., \& Gottfredson, G. D. (1999). A school-based social competency promotion demonstration. Evaluation Review, 23, 3-27.

Snyder, H. N. (2000, December). Juvenile arrests, 1999. Juvenile Justice Bulletin (Report No. NCJ 185236). Washington, DC: U.S. Department of Justice, Office of Juvenile Justice and Delinquency Prevention.

Sprague, J., Walker, H., Golly, A., White, K., Myers, D., \& Shannon, T. (2001). Translating research into effective practice: The effects of a universal staff and student intervention on indicators of discipline and school safety. Education and Treatment of Children, 24, 495-511.

Sugai, G., \& Horner, R. H. (1994). Including students with severe behavior problems in general education settings: Assumptions, challenges, and solutions. In J. Marr, G. Sugai, \& B. Tindal (Eds.), The Oregon Conference monograph (Vol. 6, pp. 102-120). Eugene, OR: College of Education, University of Oregon.

Thornton, T. N., Craft, C. A., Dahlberg, L. L., Lynch, B. S., \& Baer, K. (2000). Best practice of youth violence prevention: A sourcebook for community action. Atlanta, GA: Center for Disease Control and Prevention, National Center for Injury Prevention and Control.

Tingstrom, D. H. (1994). The good behavior game: An investigation of teachers' acceptance. Psychology in the Schools, 31(1), 57-65.

Tolan, P. H. (2001). Emerging themes and challenges in understanding youth violence involvement. Journal of Clinical Child Psychology, 30, 233-239.

Tolan, P. H., \& Guerra, N. (1994). What works in reducing adolescent violence: An empirical review of the field. Boulder, CO: University of Colorado at Boulder, Center for the Study and Prevention of Violence.

Umbreit, M. S., \& Kruk, E. (1997). Parents and children. In E. Kruk(Ed.), Mediation and conflict resolution in social work and human services (pp. 97-115). Chicago: Nelson-Hall.

U.S. Surgeon General. (2001). Youth violence: A report of the Surgeon General. Washington, DC: Department of Health and Human Services.

Wahler, J. J., Fetsch, R. J., \& Silliman, B. (1997). Research-based, empirically-effective violence prevention curricula: A review of resources. Retrieved February 8, 2002, from http:// www.nnfr.org/violence/yvp_litrev.html

Walker, H. M., Colvin, G., \& Ramsey, E. (1995). Antisocial behavior in school: Strategies and best practices. Pacific Grove, CA: Brooks/Cole.

Walker, H., Hops, H., \& Greenwood, C. (1993). RECESS: A program for reducing negativeaggressive behavior. Seattle, WA: Educational Achievement Systems.

Watson, A. L., Williams, J. E., \& Ball, A. (2001). Workplace violence: Another face of the crisis. In D. Sandhu (Ed.), Faces of violence: Psychological correlates, concepts and intervention strategies (pp. 3-21). Huntington, NY: Nova Science Publishers.

Young, K. R., West, R. P., Smith, D. J., \& Morgan, D. P. (1991). Teaching self-management strategies to adolescents. Longmont, CO: Sopris West.

Mark A. Mattaini, DSW, ACSW, is an associate professor and director of the Ph.D. in Social Work Program, Jane Addams College of Social Work, University of Illinois at Chicago. Dr. Mattaini received his MSW from the University of Utah in 1978, and his Doctor of Social Welfare from Columbia University in New York in 1990. He has also been on the faculty at Columbia University and the University of Wisconsin-Milwaukee. Dr. Mattaini has extensive professional practice experience in youth services, family and community practice, and mental health. He is author or editor of 8 books and over 60 other publications; Chair of Behaviorists for Social Responsibility, a special interest 


\section{BEHAVIOR MODIFICATION / March 2006}

group of the Association for Behavior Analysis International; and Editor of the journal Behavior and Social Issues.

Melissa McGuire, MPH, MSW, is a doctoral student at Jane Addams College of Social Work, University of Illinois at Chicago. She earned her master's degree in Public Health at Tulane, where her studies focused on International Health and Development. She earned her MSW at Jane Addams College of Social Work. She has worked in Peace Education with the Quaker Peace Center in Mowbray, South Africa, and also spent nearly 7 years as part of a drug discovery team where she published in the areas of ethnobotany and novel drug discovery. In conjunction with her doctoral studies, Ms. McGuire is currently working with the PEACE POWER Project at UIC, as well as with the City at Peace-Chicago program. 